\title{
RHIPICEPHALUS MICROPLUS \\ AND ITS VECTOR-BORNE HAEMOPARASITES IN GUINEA: FURTHER SPECIES EXPANSION IN WEST AFRICA
}

\author{
Makenov $\mathrm{MT}^{1}$, Toure $\mathrm{AH}^{2}$, Korneev $\mathrm{MG}^{3}$, Sacko $\mathrm{N}^{4}$, Porshakov $\mathrm{AM}^{3}$, Yakovlev $\mathrm{SA}^{3}$, \\ Radyuk $\mathrm{EV}^{1}$, Zakharov $\mathrm{KS}^{3}$, Shipovalov $\mathrm{AV}^{5}$, Boumbaly $\mathrm{S}^{4}$, Zhurenkova $\mathrm{OB}^{1}$, \\ Grigoreva $\mathrm{YaE}^{1}$, Morozkin $\mathrm{ES}^{1}$, Fyodorova $\mathrm{MV}^{1}$, Boiro $\mathrm{MY}^{2}$, Karan $\mathrm{LS}^{1}$
}

${ }^{1}$ - Central Research Institute of Epidemiology, Moscow, Russia

${ }^{2}$ - Research Institute of Applied Biology of Guinea, Kindia, Guinea

${ }^{3}$ - Russian Research Anti-Plague Institute "Microbe», Saratov, Russia

${ }^{4}$ - International Center for Research of Tropical Infections in Guinea, N'Zerekore, Guinea

${ }^{5}$ - State Research Center of Virology and Biotechnology "Vector», Kol'tsovo, Russia

\section{ABSTRACT}

Rhipicephalus microplus is an ixodid tick with a pantropical distribution that represents a serious threat to livestock. West Africa was free of this tick until 2007, when its introduction into Benin was reported. Shortly thereafter, the further invasion of this tick into West African countries was demonstrated. In this paper, we describe the first detection of R. microplus in Guinea and list the vector-borne haemoparasites that were detected in the invader and indigenous Boophilus species.

In 2018, we conducted a small-scale survey of ticks infesting cattle in three administrative regions of Guinea: N'Zerekore, Faranah, and Kankan. The tick species were identified by examining their morphological characteristics and by sequencing their COI gene and ITS-2 gene fragments. R. microplus was found in each studied region. In the ticks, we found DNA of Babesia bigemina, Anaplasma marginale, Anaplasma platys, and Ehrlichia spp. The results of this study indicate that R. microplus was introduced into Guinea with cows from Mali and/or Ivory Coast.

\section{KEYWORDS}

Ticks, Invasive species, Rhipicephalus microplus, Boophilus, Babesia, Anaplasma, Ehrlichia 


\section{INTRODUCTION}

Rhipicephalus

microplus

(Canestrini, 1888) (formerly Boophilus microplus) is an ixodid tick species with a one-host life cycle that parasitizes a variety of livestock species. R. microplus is the most commercially important tick species distributed in tropical and subtropical regions of the world (Frisch 1999; Labruna et al. 2009). In Africa, this tick has been established in much of southern and eastern Africa, including such countries as South Africa, Mozambique, Zimbabwe, Malawi, Zambia, Tanzania, and Kenya (Walker et al. 2003). Since 2007, R. microplus has been detected in West Africa, specifically Ivory Coast (Madder et al. 2007) and Benin (de Clercq et al. 2012; Madder et al. 2012). Soon after these findings, several papers confirmed the further invasion of the species in West Africa: R. microplus was detected in Burkina Faso, Togo, Mali (Adakal et al. 2013), Nigeria (Kamani et al. 2017), and Cameroon (Silatsa et al. 2019).

The rapid spread of $R$. microplus in West Africa entails a negative impact on the livestock sector. Heavy infestation of cattle with this tick causes weight loss, reduced milk production and increased cow mortality (Corrier et al. 1979; Guerrero et al. 2007; Madder et al. 2011; Rocha et al. 2011; da Silva et al. 2013). Furthermore, R.microplus causes considerable losses in cattle as a vector of several pathogens, including Babesia bigemina, Babesia bovis, Anaplasma marginale, and Ehrlichia ruminantium (Guerrero et al. 2007; Biguezoton et al. 2016).

In the Guinea sub-genus, Boophilus was represented by three species: R. annulatus (Say, 1821), R. decoloratus (Koch, 1844), and R. geigyi (Aeschliman \& Morel, 1965) (Konstantinov et al. 1990; Walker et al. 2003; Bouaro et al. 2013). R. microplus has not been detected in Guinea previously. In this paper, we confirm the presence of $R$. microplus in Guinea and list the vector-borne haemoparasites that were detected in the invader and indigenous Boophilus species.

\section{METHODS}

In April-May 2018, we conducted a small-scale survey of ticks infesting cattle in three administrative regions of Guinea: N'Zerekore, Faranah, Kankan. These regions are located on the eastern part of Guinea and adjoin countries where the presence of R.microplus has been confirmed previously (Mali, Ivory Coast). We collected ticks from freshly slaughtered cattle or cattle prepared for slaughtering in slaughterhouses in each region. Ticks collected from a cow were placed in a separate tube. The sampled ticks were identified to stage and species according to their morphological characteristics (Walker et al. 2003) and 
were pooled into groups of one to two for Rhipicephalus and Hyalomma species and from one to five for Amblyomma variegatum Fabricius, 1794. Pools were formed by species, sex, and animal host. Ticks were later washed with 70\% alcohol and then rinsed twice with $0.15 \mathrm{M} \mathrm{NaCl}$ solution. Each pool was homogenized with Tissuelyser LT (Qiagen, Hilden, Germany) in $500 \mu \mathrm{l}$ of $0.15 \mathrm{M} \mathrm{NaCl}$ solution. Thereafter, DNA/RNA was extracted from $100 \mu \mathrm{l}$ of the $10 \%$ tick suspension using a commercial AmpliSens RIBO-prep kit (Central Research Institute of Epidemiology, Moscow, Russia) following the manufacturer's instructions.

To check the tick species diagnoses based on morphological characteristics, we sequenced the $\mathrm{COI}$ gene fragments for each R. microplus and for several voucher specimens for other tick species using primers described previously (Geller et al. 2013; Makenov et al. 2019). Additionally, we sequenced the ITS-2 gene fragments for R.microplus specimens using the following primers: 58S F3/1: $5^{\prime}-$ GGGTCGATGAAGAACGCAGCCAGC-3'

(Fukunaga et al. 1995) and ST-ITS2-R2: 5'-AACCGAGTRCGACGCCCTACCA-3' (selfdesigned).

Since the primary topic of this paper is the invasion of R. microplus in
Guinea, we investigated the subgenus Boophilus; other tick species (A. variegatum and Hyalomma truncatum, Koch, 1844) were excluded from further consideration. Additionally, R. microplus parasitizes only cattle and wild ungulates; consequently, we focused this paper on haemoparasites of cattle and did not consider other vectorborne pathogens. We screened for the presence of Babesia spp. with primers Bs1 and Bs2 (18S rRNA gene) according to Rar et al. (2011) and by qPCR (Michelet et al. 2014) (see primers and probes in Table 1). Additionally, we used qPCR to screen Theileria annulata (Michelet et al. 2014) (see primers and probes in Table 1). To detect bacteria of the Anaplasmataceae family, we used primers Ehr1, Ehr2, Ehr3, and Ehr4 (16S rRNA gene) according to (Rar et al. 2010). The identification of Anaplasma marginale was additionally confirmed by sequencing of the groEL gene fragment: the assay was conducted in a nested format with primers HS1-f and HS6-r (Rar et al. 2010) in the first round and primers HS3-f HSVR in the nested reactions (Liz et al. 2000). Furthermore, we employed qPCR to screen A. marginale, A. ovis, and A. centrale (Michelet et al. 2014) (see primers and probes in Table 1). 
Table 1. Oligonucleotide sequences of the primers and probes used in qPCR amplification of Anaplasma spp. and Babesia spp.(according to Michelet et al (Michelet et al. 2014))

\begin{tabular}{|c|c|c|c|}
\hline \multirow[t]{2}{*}{ Name } & \multirow{2}{*}{$\begin{array}{l}\text { Nucleotide sequence } \\
5^{\prime}-3^{\prime}\end{array}$} & \multicolumn{2}{|l|}{ Target } \\
\hline & & Gene & Species \\
\hline \multicolumn{4}{|c|}{ Anaplasma mix } \\
\hline An_ma_msp1_F & CAGGCTTCAAGCGTACAGTG & msp1b & Anaplasma marginale \\
\hline An_ma_msp1_R & GATATCTGTGCCTGGCCTTC & & \\
\hline An_ma_msp1_p & ATGAAAGCCTGGAGATGTTAGACCGAG & & \\
\hline An_ov_msp4_F & TCATTCGACATGCGTGAGTCA & msp4 & Anaplasma ovis \\
\hline An_ov_msp4_R & TTTGCTGGCGCACTCACATC & & \\
\hline An_ov_msp4_p & AGCAGAGAGACCTCGTATGTTAGAGGC & & \\
\hline An_cen_groEL_F & AGCTGCCCTGCTATACACG & groEL & Anaplasma centrale \\
\hline An_cen_groEL_R & GATGTTGATGCCCAATTGCTC & & \\
\hline An_cen_groEL_p & CTTGCATCTCTAGACGAGGTAAAGGGG & & \\
\hline \multicolumn{4}{|c|}{ Babesia mix } \\
\hline Ba_big_RNA18S_F & ATTCCGTTAACGAACGAGACC & 18SrRNA & Babesia bigemina \\
\hline Ba_big_RNA18S_R & TTCCCCCACGCTTGAAGCA & & \\
\hline Ba_big_RNA18S_p & CAGGAGTCCCTCTAAGAAGCAAACGAG & & \\
\hline Ba_ov_RNA18S_F & TCTGTGATGCCCTTAGATGTC & 18SrRNA & Babesia ovis \\
\hline Ba_ov_RNA18S_R & GCTGGTTACCCGCGCCTT & & \\
\hline Ba_ov_RNA18S_P & TCGGAGCGGGGTCAACTCGATGCAT & & \\
\hline Ba_maj_CCTeta_F & CACTGGTGCGCTGATCCAA & CCTeta & Babesia major \\
\hline Ba_maj_CCTeta_R & TCCTCGAAGCATCCACATGTT & & \\
\hline Ba_maj_CCTeta_p & AACACTGTCAACGGCATAAGCACCGAT & & \\
\hline \multicolumn{4}{|c|}{ Theileria mix } \\
\hline Th_an_18S_F & GCGGTAATTCCAGCTCCAATA & 18SrRNA & Theileria annulata \\
\hline Th_an_18S_R & AAACTCCGTCCGAAAAAAGCC & & \\
\hline Th_an_18S_P & ACATGCACAGACCCCAGAGGGACAC & & \\
\hline
\end{tabular}

Sequencing was conducted using BigDye Terminator v1.1 Cycle Sequencing kit (Thermo Fisher Scientific, Austin, TX, USA) on an Applied Biosystems 3500xL Genetic Analyzer (Applied Biosystems, Foster City, CA, USA). The obtained sequences were deposited in NCBI GenBank under the following accession numbers: MT107445-MT107461 R. microplus COI gene fragments; MT107428, MT107430, MT107433MT107444 - R.geigyi COI gene fragments; MT107429, MT107431-
MT107432 - R. annulatus COI gene fragments; MT112107-MT112110 R. microplus ITS-2 gene fragments; MT112111-MT112112 - R. geigyi ITS-2 gene fragments; and MW042697MW042698 - A. platys 16S rRNA gene fragments; MW042699-MW042705 A. marginale 16S rRNA gene fragments; MW042706 - Ehrlichia sp. 16S rRNA gene fragments; MW054555-MW054558 - Ehrlichia sp. groEL gene fragments; and MW049239-MW049240 - Babesia bigemina $18 \mathrm{~S}$ rRNA gene fragments. 


\section{RESULTS}

A total of 40 cows were examined: 17 in Faranah, 10 in N'Zerekore, and 13 in Kankan. In total, 561 ticks of six species were collected (Table 2). The sub-genus Boophilus was represented in the sample by three species, including R. microplus,
R. annulatus, and R. geigyi (Table 2). $R$. microplus was found on cows from eight different villages located in all three studied administrative regions (Fig. 1). We found either adult ticks or eggs: one female of $R$. microplus began oviposition in the tube.

Table 2. Number of ticks collected from cattle in three administrative regions of Guinea in April-May 2018

\begin{tabular}{lcccc}
\hline \multicolumn{1}{c}{ Species } & Faranah & N'Zerekore & Kankan & Total \\
\hline Amblyomma variegatum & 441 & 61 & 0 & 502 \\
Hyalomma truncatum & 7 & 0 & 0 & 7 \\
Rhipicephalus annulatus & 6 & 0 & 0 & 6 \\
Rhipicephalus geigyi & 17 & 0 & 11 & 28 \\
Rhipicephalus microplus & 2 & 4 & 10 & 16 \\
Rhipicephalus (Boophilus) spp. & 0 & 0 & 2 & 2 \\
Total & 473 & 65 & 23 & 561 \\
\hline
\end{tabular}

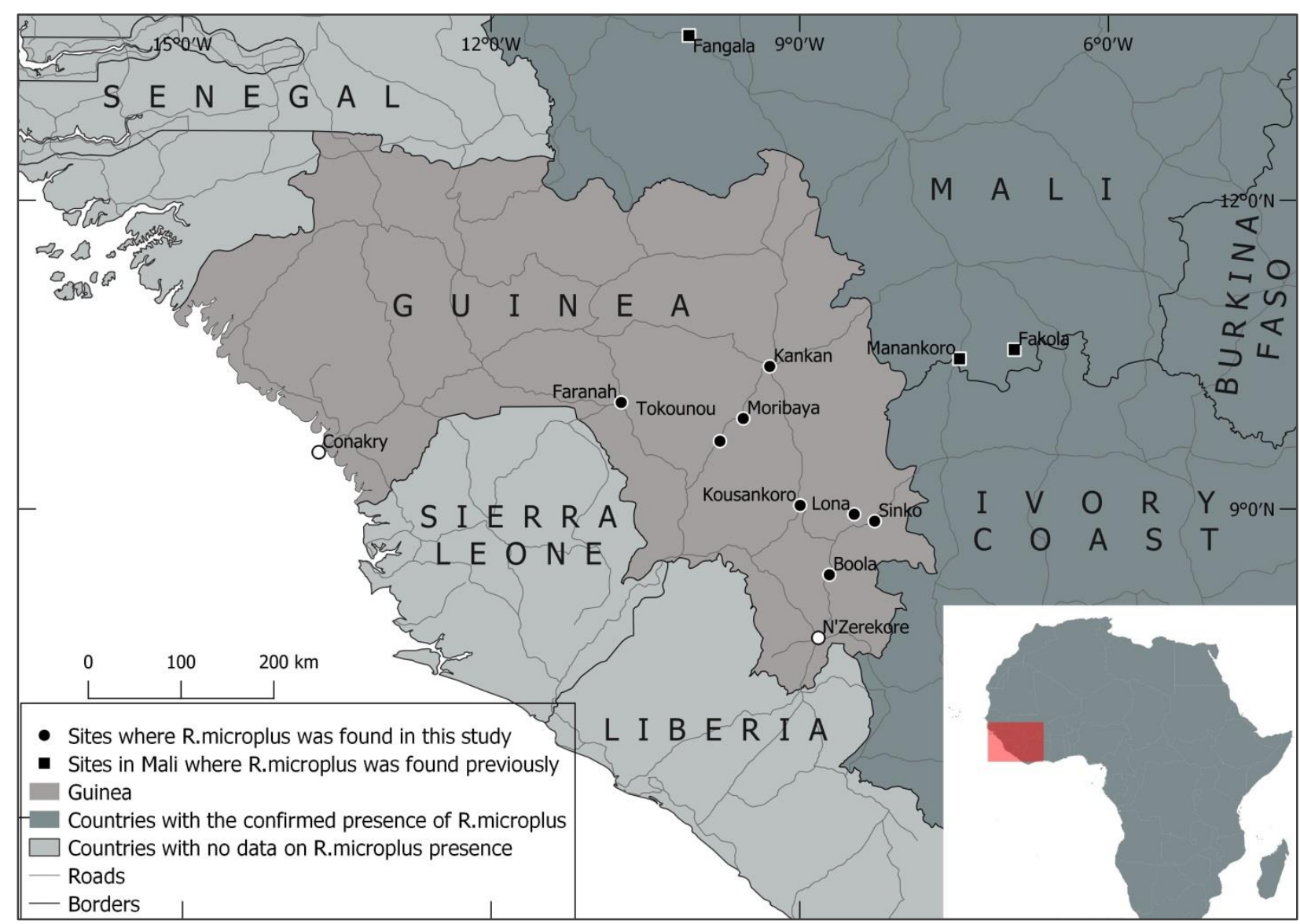

Fig. 1 Rhipicephalus microplus in Guinea and surrounding countries 
Sequencing of the COI and ITS-2 genes confirmed the morphological identification of R.microplus. BLAST analysis of these sequences revealed $100 \%$ identity with the sequences of $R$. microplus available in the GenBank database, including the $\mathrm{COI}$ gene sequence of $R$. microplus from Benin (accession number KY678120).

Screening of Babesia spp. showed the presence of Babesia bigemina DNA in R. microplus only (Table 3 ). Four infected ticks were collected from two cows in two different villages in the Kankan region. Furthermore, B. bigemina was also detected in samples of eggs of R. microplus. Two other species of protozoan haemoparasites, Theileria annulata and Theileria parva were not found in the studied ticks (Table 3).

Anaplasma marginale was found in R. microplus and in R. geigyi collected in the N'Zerekore and Kankan regions. Additionally, two females of R. microplus (from Faranah and Kankan) were infected with A. platys (Table 3). We also found Ehrlichia spp. in four ticks collected from a host cow in Faranah. The obtained sequences of groEL and $16 \mathrm{~S}$ rRNA genes enable us to identify the pathogen at the genus level only. Most similar sequences from GenBank belong to uncultured Ehrlichia isolated from ticks in China and Tajikistan: 97.7\% identity on the groEL gene with Ehrlichia spp. isolated from ticks in Tajikistan (GenBank accession number KJ930191) and $99.8 \%$ identity on the $16 \mathrm{~S}$ rRNA gene with Ehrlichia spp. isolated from ticks in Niger, Malaysia, China, and Thailand (GenBank accession numbers AF311968, KY046298, KJ410255, and AF497581, respectively).

Table 3. Results of PCR screening on Babesia bigemina, Theileria annulata, Theileria parva and bacteria of the Anaplasmatacea family in ticks of the Boophilus sub-genus

\begin{tabular}{lcccccccc}
\hline Tick species & $\begin{array}{c}\text { No of } \\
\text { studied } \\
\text { ticks }\end{array}$ & $\begin{array}{c}\text { No of } \\
\text { cows }^{a}\end{array}$ & $\begin{array}{c}\text { B. } \\
\text { bigemina }\end{array}$ & T. annulata & $\begin{array}{c}\text { No of PCR-positive on } \\
\text { T. parva }\end{array}$ & A. marginale & A. platys & $\begin{array}{c}\text { Ehrlichia } \\
\text { spp }\end{array}$ \\
\hline R. microplus & $17^{b}$ & 11 & $5^{b}$ & 0 & 0 & 9 & 2 & 0 \\
R. geigyi & 23 & 10 & 0 & 0 & 0 & 9 & 0 & 3 \\
R. annulatus & 3 & 3 & 0 & 0 & 0 & 0 & 0 & 1 \\
Total & 43 & $23^{c}$ & 5 & 0 & 0 & 18 & 2 & 4 \\
\hline
\end{tabular}

a - the number of cows from which the studied ticks were collected

${ }^{b}$ - including specimens with eggs of $R$. microplus

c - from a cow we collected both R. geigyi and R. annulatus; therefore, the total number of cows is less than the sum of values in cells above 


\section{DISCUSSION}

The spread of $R$. microplus in West African countries is associated with the transfer of livestock between countries (Madder et al. 2012; Adakal et al. 2013). Evidently, R. microplus also appeared in Guinea with cattle imported from neighbouring countries. Guinean veterinarians confirmed that farmers buy cows every year in Mali, Ivory Coast, and Senegal. In particular, we detected R. microplus in Beyla Prefecture (N'Zerekore region), and since 2011, local farmers have purchased cattle, including cows of the breed Girolando, from Mali with transfers via the Ivory Coast. According to Adakal et al (2013), R. microplus was found in three villages in Mali in 2011. Two of these villages (Manankoro and Fakola) are located approximately 200-250 km from Beyla Prefecture. Furthermore, the N'Zerekore and Kankan regions share a border with the Ivory Coast (Denguele and Woroba Districts), where R.microplus was also detected (Boka et al. 2017). Therefore, we hypothesize that R. microplus was introduced into Guinea with cows from Mali and/or Ivory Coast.

Previously, it was shown that the introduction of R.microplus to new territories could lead to displacement of the native Boophilus species (Macleod and Mwanaumo 1978; Wedderburn et al. 1991; Berkvens et al. 1998; Tønnesen et al. 2004). In West Africa, the displacement of $R$. decoloratus and $R$. geigyi was observed in the Ivory Coast (Madder et al. 2011; Boka et al. 2017) and Benin (De Clercq et al. 2012). We found ticks of the subgenus Boophilus in samples from nine Guinean villages, and in eight of them, R. microplus was detected. The simultaneous presence of $R$. microplus with other species of the subgenus was observed in Tokounou village (Kankan region) and in Faranah. Due to a lack of sampling efforts, we could not assess the replacement of native species of the Boophilus subgenus. However, the detection of $R$. microplus and R. geigyi in the same village indicates that the displacement process had not begun or was in an early stage.

De Clercq et al. (2013) calculated a climate suitability map for $R$. microplus in West Africa. According to the model of these researchers, the species' potential range covers the southern part of Guinea: N'Zerekore region and parts of Kankan, Faranah, and Kindia regions (De Clercq et al. 2013), and our findings of $R$. microplus correlate well with the predicted suitable area. Liberia and Sierra also belong to territories with high climate suitability for R. microplus (De Clercq et al. 2013), but the species has not been detected in these countries to date. Considering the transparency of borders between Guinea, Liberia, and Sierra Leone, it can be assumed that 
R. microplus will be detected in these countries in a short time.

Babesia bigemina is common haemoparasite of cattle in Africa (Bock et al. 2004; Reye et al. 2012; Beckley et al. 2016; Kamani et al. 2017) and was detected in Nigeria (llemobade 1991), Ghana (Bell-Sakyi et al. 2004), and Guinea (De Meneghi et al. 2000). Theileria parva and Theileria annulata cause severe for domestic ruminants theileriosis transmitted by Rhipicephalus appendiculatus and by ticks which belong to the genus Hyalomma (Dolan 1989). Ticks of Boophilus species are not competent vectors of these two Theileria species, but engorged ticks might contain not only pathogens for which they are competent vectors but also other pathogens that circulate in the blood of the host at the time of tick feeding. For this reason, we screened collected ticks for the presence of Theileria parva and Theileria annulata. As a result, these pathogens were not detected in the collected ticks.

Babesia bigemina causes infections in livestock, and R. microplus is its competent vector. However, indigenous Boophilus species (R. geigyi, R. annulatus) are also able to transmit B. bigemina and had taken part in the pathogen circulation in West Africa before the invasion of R. microplus (llemobade 1991; Bell-Sakyi et al. 2004). According to Tomassone et al (2004), B. bigemina was found in $21.1 \%$ of blood smears taken from cattle in Guinea in 2000. No published research is available concerning tick-borne haemoparasites in ticks in Guinea, and we are not able to determine how the prevalence of the pathogens changed after the introduction of $R$. microplus.

\section{Anaplasma marginale is a} worldwide tick-borne disease of cattle that is characterized by progressive haemolytic anaemia, abortions, loss of condition, milk production, and death (Ristic 1981). In West Africa, A. marginale was detected in ticks and cattle in Senegal (Dahmani et al. 2019), Ivory Coast (Ehounoud et al. 2016), Benin (Adjou Moumouni et al. 2018a, b), and Nigeria (Ilemobade 1991; Reye et al. 2012; Lorusso et al. 2016). In Guinea, the prevalence of $A$. marginale in cattle in 2000 was 5.6\% (Tomassone et al. 2004). Thus, the pathogen was presented in Guinea earlier, prior to the introduction of R. microplus. Anaplasma platys is primarily a pathogen of canines (Rymaszewska and Grenda 2008), but it was also found in cattle (Lorusso et al. 2016; Dahmani et al. 2019). Therefore, we hypothesize that the ticks obtained the pathogen from the blood of infected host animals.

We did not find Ehrlichia ruminantium, another important veterinary tick-borne pathogen, in our samples. Within the Ehrlichia genus, we 
found only uncultured genotypes in four ticks collected from the same cow. The sequences of $16 \mathrm{~S}$ rRNA and groEl genes did not enable us to identify the pathogen at the species level. Further study of the molecular identification of this Ehrlichia spp. is needed.

\section{CONCLUSION}

We reported the presence of R. microplus in Guinea and confirmed its further invasion in West African countries. The main route of species expansion is the transfer of cattle among countries without proper veterinary control. Most researchers who detected $R$. microplus in West Africa noted that the introduction of this species has negative consequences for livestock, primarily due to the transmission of vector-borne pathogens. We detected six pathogens in ticks, two of which, B. bigemina and A.marginale, cause severe diseases in cattle. However, both of these pathogens are common for West Africa and had been circulating in Guinea before the introduction of R. microplus. Nevertheless, the invasion of a new species of tick might change the composition of circulating pathogens and their prevalence. As a consequence, the introduction of new species might lead to considerable losses.

Clearly, it is not possible to prevent further distribution of $R$. microplus in West Africa within a climatically suitable range. Therefore, further studies of the pathogens circulating in these territories and the acaricidal resistance of ticks are warranted.

\section{DECLARATIONS}

Funding: This research did not receive any specific grant from funding agencies in the public, commercial, or not-for-profit sectors.

Conflicts of interest/Competing interests: The authors declare that they have no conflicts of interest and/or competing interests.

Ethics approval: No ethics approval was required, as this study does not involve clinical trials or experimental procedures. The inspected cattle were slaughtered for human consumption. The slaughterhouse staff gave permission to collect ticks from animals. The Research Ethics Committee of the Central Research Institute of Epidemiology (Moscow, Russia) has confirmed that no ethics approval is required.

Availability of data and material (data transparency): The authors confirm that the data supporting the findings of this study are available within the article [.

\section{REFERENCES}

1. Adakal $H$, Biguezoton $A$, Zoungrana $S$, et al (2013) Alarming spread of the Asian cattle tick Rhipicephalus microplus in West Africa-another three countries are affected: Burkina Faso, Mali and Togo. Exp Appl Acarol 61:383-386. https://doi.org/10.1007/s10493-013-9706-6

2. Adjou Moumouni PF, Aplogan GL, Katahira H, et al (2018a) Prevalence, risk factors, and genetic diversity of veterinary important tickborne pathogens in cattle from Rhipicephalus microplus-invaded and non-invaded areas of Benin. Ticks Tick Borne Dis 9:. https://doi.org/10.1016/j.ttbdis.2017.12.015

3. Adjou Moumouni PF, Guo H, Gao Y, et al 
(2018b) Identification and genetic characterization of Piroplasmida and Anaplasmataceae agents in feeding Amblyomma variegatum ticks from Benin. Vet Parasitol Reg Stud Reports 14:137-143. https://doi.org/10.1016/J.VPRSR.2018.10.006

4. Beckley CS, Shaban S, Palmer GH, et al (2016) Disaggregating tropical disease prevalence by climatic and vegetative zones within tropical west Africa. PLoS One 11:1-13. https://doi.org/10.1371/journal.pone.0152560

5. Bell-Sakyi L, Koney EBM, Dogbey O, Walker AR (2004) Incidence and prevalence of tick-borne haemoparasites in domestic ruminants in Ghana. Vet Parasitol 124:25-42. https://doi.org/10.1016/j.vetpar.2004.05.027

6. Berkvens DL, Geysen DM, Chaka G, et al (1998) A survey of the ixodid ticks parasitising cattle in the Eastern province of Zambia. Med Vet Entomol $12: 234-240$ https://doi.org/10.1046/j.1365-

2915.1998.00106.x

7. Biguezoton A, Noel V, Adehan S, et al (2016) Ehrlichia ruminantium infects Rhipicephalus microplus in West Africa. Parasites and Vectors 9:4-7. https://doi.org/10.1186/s13071-0161651-x

8. Bock R, Jackson L, De Vos A, Jorgensen W (2004) Babesiosis of cattle. Parasitology 129: https://doi.org/10.1017/\$0031182004005190

9. Boka OM, Achi L, Adakal H, et al (2017) Review of cattle ticks (Acari, Ixodida) in Ivory Coast and geographic distribution of Rhipicephalus (Boophilus) microplus, an emerging tick in West Africa. Exp Appl Acarol 71:355-369. https://doi.org/10.1007/s10493-017-0129-7

10. Bouaro MY, Kalivogui S, Konstantinov OK, et al (2013) Seroepiemiological and epizootological study of tick-borne rickettsioses in republic of Guinea. Pest Manag 22-28

11. Corrier DE, Vizcaino O, Terry M, et al (1979) Mortality, weight loss and anaemia inBos taurus calves exposed to Boophilus microplus ticks in the tropics of Colombia. Trop Anim Health Prod 11:215-221. https://doi.org/10.1007/BF02237806
12. Da Silva JB, Rangel CP, de Azevedo Baêta B, da Fonseca AH (2013) Influence of the physiological state on infestation by Rhipicephalus microplus in dairy cows. Ticks Tick Borne Dis 4:52-56. https://doi.org/10.1016/J.TTBDIS.2012.07.003

13. Dahmani M, Davoust B, Sambou M, et al (2019) Molecular investigation and phylogeny of species of the Anaplasmataceae infecting animals and ticks in Senegal. Parasites and Vectors 12:1-15. https://doi.org/10.1186/s13071-019-3742-y

14. De Clercq EM, Estrada-Peña A, Adehan S, et al (2013) An update on distribution models for Rhipicephalus microplus in West Africa. Geospat Health 8:301-308. https://doi.org/10.4081/gh.2013.75

15. De Clercq EM, Vanwambeke SO, Sungirai M, et al (2012) Geographic distribution of the invasive cattle tick Rhipicephalus microplus, a country-wide survey in Benin. Exp Appl Acarol 58:441-452. https://doi.org/10.1007/s10493012-9587-0

16. De Meneghi D, Pagani P, Diallo OH, Cavallo E (2000) Infestation by ticks (Ixodidae) and infection by tick-borne haemoparasites in N'Dama cattle affected by" Woula" in Guinea Conakry. Parassitologia 197-197

17. Dolan TT (1989) Theileriasis: a comprehensive review. Rev Sci Tech I'OIE 8:11-78. https://doi.org/10.20506/rst.8.1.398

18. Ehounoud CB, Yao KP, Dahmani M, et al (2016) Multiple Pathogens Including Potential New Species in Tick Vectors in Côte d'Ivoire. PLoS Negl Trop Dis 10:e0004367. https://doi.org/10.1371/journal.pntd.0004367

19. Frisch JE (1999) Towards a permanent solution for controlling cattle ticks. Int J Parasitol 29:57$71 . \quad$ https://doi.org/10.1016/S00207519(98)00177-5

20. Fukunaga $M$, Takahash $Y$, Tsuruta $Y$, et al (1995) Genetic and phenotypic analysis of Borrelia miyamotoi sp. nov., isolated from the Ixodid tick Ixodes persulcatus, the vector for Lyme disease in Japan. Int J Syst Bacteriol 45:804-810 
21. Geller J, Meyer C, Parker M, Hawk H (2013) Redesign of PCR primers for mitochondrial cytochrome c oxidase subunit I for marine invertebrates and application in all-taxa biotic surveys. Mol Ecol Resour 13:851-861. https://doi.org/10.1111/1755-0998.12138

22. Guerrero FD, Bendele KG, Davey RB, George JE (2007) Detection of Babesia bigemina infection in strains of Rhipicephalus (Boophilus) microplus collected from outbreaks in South Texas. Vet Parasitol 145:156-163. https://doi.org/10.1016/J.VETPAR.2006.11.014

23. Ilemobade AA (1991) Anaplasmosis, babesiosis and cowdriosis in the West African sub-region: distribution, economic importance and control measures. In: Proceedings of a Workshop Held as ILRAD Nairobi Kenya. pp 43-47

24. Kamani J, Apanaskevich DA, Gutiérrez R, et al (2017) Morphological and molecular identification of Rhipicephalus (Boophilus) microplus in Nigeria, West Africa: a threat to livestock health. Exp Appl Acarol 73:283-296. https://doi.org/10.1007/s10493-017-0177-z

25. Konstantinov OK, Balde MC, Tchounina LM, et al (1990) Les tiques de la famille Ixodidae comme réservoir d'arbovirus en République de Guinée. 1. Faune et ecologie des tiques. Rev Elev Méd vét Pays Trop 43:85-92

26. Labruna MB, Naranjo $V$, Mangold AJ, et al (2009) Allopatric speciation in ticks: Genetic and reproductive divergence between geographic strains of Rhipicephalus (Boophilus) microplus. BMC Evol Biol 9:1-12. https://doi.org/10.1186/1471-2148-9-46

27. Liz JS, Anderes L, Sumner JW, et al (2000) PCR detection of granulocytic Ehrlichiae in Ixodes ricinus ticks and wild small mammals in Western Switzerland. J Clin Microbiol 38:10021007

28. Lorusso $\mathrm{V}$, Wijnveld $\mathrm{M}$, Majekodunmi $\mathrm{AO}$, et al (2016) Tick-borne pathogens of zoonotic and veterinary importance in Nigerian cattle. Parasites and Vectors 9:1-13. https://doi.org/10.1186/s13071-016-1504-7

29. Macleod J, Mwanaumo B (1978) Ecological studies of ixodid ticks (Acari: Ixodidae) in
Zambia. IV. Some anomalous infestation patterns in the northern and eastern regions. Bull Entomol Res 68:409-429. https://doi.org/10.1017/\$0007485300009391

30. Madder M, Adehan S, De Deken R, et al (2012) New foci of Rhipicephalus microplus in West Africa. Exp Appl Acarol 56:385-390. https://doi.org/10.1007/s10493-012-9522-4

31. Madder M, Thys E, Achi L, et al (2011) Rhipicephalus (Boophilus) microplus: A most successful invasive tick species in West-Africa. Exp Appl Acarol 53:139-145. https://doi.org/10.1007/s10493-010-9390-8

32. Madder M, Thys E, Geysen D, et al (2007) Boophilus microplus ticks found in West Africa. Exp Appl Acarol 43:233-234. https://doi.org/10.1007/s10493-007-9110-1

33. Makenov M, Karan L, Shashina N, et al (2019) First detection of tick-borne encephalitis virus in Ixodes ricinus ticks and their rodent hosts in Moscow, Russia. Ticks Tick Borne Dis 10:101265.

https://doi.org/10.1016/j.ttbdis.2019.101265

34. Michelet L, Delannoy S, Devillers E, et al (2014) High-throughput screening of tick-borne pathogens in Europe. Front Cell Infect Microbiol https://doi.org/10.3389/fcimb.2014.00103

35. Rar VA, Epikhina TI, Livanova NN, Panov V V. (2011) Genetic diversity of Babesia in Ixodes persulcatus and small mammals from North Ural and West Siberia, Russia. Parasitology 138:175-182.

https://doi.org/10.1017/\$0031182010001162

36. Rar VA, Livanova NN, Panov V V., et al (2010) Genetic diversity of Anaplasma and Ehrlichia in the Asian part of Russia. Ticks Tick Borne Dis 1:57-65.

https://doi.org/10.1016/J.TTBDIS.2010.01.002

37. Reye AL, Arinola OG, Hübschen JM, Muller CP (2012) Pathogen prevalence in ticks collected from the vegetation and livestock in Nigeria. Appl Environ Microbiol 78:2562-2568. https://doi.org/10.1128/AEM.06686-11

38. Ristic M (1981) Anaplasmosis. In: Ristic M, McIntyre I (eds) Diseases of Cattle in the 
Tropics: Economic and Zoonotic Relevance.

Springer Netherlands, Dordrecht, pp 327-344

39. Rocha CMBM da, Leite RC, Bruhn FRP, et al (2011) Perceptions of milk producers from Divinópolis, Minas Gerais, regarding Rhipicephalus (Boophilus) microplus control. Rev Bras Parasitol Veterinária 20:295-302. https://doi.org/10.1590/S198429612011000400007

40. Rymaszewska A, Grenda S (2008) Bacteria of the genus Anaplasma - characteristics of Anaplasma and their vectors: a review. Vet Med (Praha) 53:573-584. https://doi.org/10.17221/106/2009-VETMED

41. Silatsa BA, Kuiate JR, Njiokou F, et al (2019) A countrywide molecular survey leads to a seminal identification of the invasive cattle tick Rhipicephalus (Boophilus) microplus in Cameroon, a decade after it was reported in Cote d'Ivoire. Ticks Tick Borne Dis 10:585-593. https://doi.org/10.1016/j.ttbdis.2019.02.002

42. Tomassone L, Camicas JL, Pagani P, et al (2004) Monthly dynamics of ticks (Acari: Ixodida) infesting N'Dama cattle in the Republic of Guinea. Exp Appl Acarol 32:209-218. https://doi.org/10.1023/B:APPA.0000021771.3 4520.ab

43. Tønnesen MH, Penzhorn BL, Bryson NR, et al (2004) Displacement of Boophilus decoloratus by Boophilus microplus in the Soutpansberg region, Limpopo Province, South Africa. Exp. Appl. Acarol. 32:199-208

44. Walker A., Bouattour A, Camicas J., et al (2003) Ticks of domestic animals in Africa: a guide to identification of species

45. Wedderburn PA, Jagger TD, McCartan B, Hunter AG (1991) Distribution of Boophilus species ticks in Swaziland. Trop Anim Health Prod 23:167-171. https://doi.org/10.1007/BF02356999 